\title{
The Localization of the Brain-Specific Inorganic Phosphate Transporter Suggests a Specific Presynaptic Role in Glutamatergic Transmission
}

\author{
Elizabeth E. Bellocchio, ${ }^{1}$ Hailan Hu, ${ }^{1}$ Alicia Pohorille, ${ }^{2}$ June Chan, ${ }^{2}$ Virginia M. Pickel, ${ }^{2}$ and \\ Robert H. Edwards ${ }^{1}$ \\ ${ }^{1}$ Departments of Neurology and Physiology, Graduate Programs in Neuroscience and Cell Biology, University of California \\ San Francisco School of Medicine, San Francisco, California 94143, and 2Department of Neurology and Neuroscience, \\ Cornell University Medical College, New York, New York 10021
}

\begin{abstract}
Molecular cloning has recently identified a vertebrate brainspecific $\mathrm{Na}^{+}$-dependent inorganic phosphate transporter (BNPI). BNPI has strong sequence similarity to EAT-4, a Caenorhabditis elegans protein implicated in glutamatergic transmission. To characterize the physiological role of BNPI, we have generated an antibody to the protein. Immunocytochemistry of rat brain sections shows a light microscopic pattern that is suggestive of reactivity in nerve terminals. Excitatory projections are labeled prominently, and ultrastructural analysis confirms that BNPI localizes almost exclusively to terminals forming asymmetric excitatory-type synapses. Although BNPI depends on a $\mathrm{Na}^{+}$gradient and presumably functions at the plasma membrane, both electron microscopy and biochemical fractionation show that BNPI associates preferentially with the
\end{abstract}

Neurons exhibit multiple transport activities that contribute to synaptic transmission. Reuptake across the plasma membrane terminates the action of classical neurotransmitters in the synaptic cleft, and transport into synaptic vesicles packages the transmitter for subsequent release by exocytosis. Neurons also actively transport a number of compounds and ions not generally considered to participate directly in signaling. These ions include inorganic phosphate $\left(\mathrm{P}_{\mathrm{i}}\right)$, which has been found to accumulate in both squid and frog neurons (Mullins, 1954; Caldwell and Lowe, 1970). More recent studies show that cortical neurons, cerebellar granule cells, and synaptosomes prepared from the rat also demonstrate $\mathrm{P}_{\mathrm{i}}$ transport, and this activity depends on a $\mathrm{Na}^{+}$gradient (Ni et al., 1994; Glinn et al., 1995; Furman et al., 1997). Although $\mathrm{P}_{\mathrm{i}}$ transport has been observed in these systems, the biological role of $\mathrm{P}_{\mathrm{i}}$ uptake by neurons remains unknown.

In the kidney, $\mathrm{Na}^{+}$-dependent $\mathrm{P}_{\mathrm{i}}$ transport is essential for the

Received May 15, 1998; revised Aug. 6, 1998; accepted Aug. 17, 1998.

This work was supported by Grants MH00078 and MH40342 from the National Institute of Mental Health (to V.M.P.), by a Howard Hughes Predoctoral Fellowship (to E.E.B.), and by National Institute of Mental Health Grant MH01365 and National Institute of Neurological Diseases and Stroke Grant NS16033 (to R.H.E.). We thank R. Y. N. Lee and L. Avery for thoughtful discussion and for communicating unpublished observations; S. E. Craven and D. S. Bredt for assistance with the hippocampal cultures; F. Chaudhry, H. J. Ralston III, and D. H. Lowenstein for help with the anatomy; R. J. Reimer for help with the graphics and review of this manuscript; and the members of the Edwards lab for technical assistance and thoughtful discussion.

Correspondence should be addressed to Dr. Robert H. Edwards, Departments of Neurology and Physiology, University of California San Francisco School of Medicine, 513 Parnassus Avenue, Box 0435, San Francisco, CA 94143-0435.

Copyright (C) 1998 Society for Neuroscience $0270-6474 / 98 / 188648-12 \$ 05.00 / 0$ membranes of small synaptic vesicles. The results provide anatomic evidence of a specific presynaptic role for BNPI in glutamatergic neurotransmission, consistent with the phenotype of eat-4 mutants. Because an enzyme known as the phosphate-activated glutaminase produces glutamate for release as a neurotransmitter, BNPI may augment excitatory transmission by increasing cytoplasmic phosphate concentrations within the nerve terminal and hence increasing glutamate synthesis. Expression of BNPI on synaptic vesicles suggests a mechanism for neural activity to regulate the function of BNPI.

Key words: inorganic phosphate transport; BNPI; synaptic vesicle; asymmetric synapse; excitatory neurotransmission; glutamate release maintenance of phosphate homeostasis (for review, see Murer and Biber, 1996). Renal brush-border epithelial cells of the proximal tubule exhibit $\mathrm{Na}^{+}$-dependent reabsorption of $\mathrm{P}_{\mathrm{i}}$ that is controlled by both hormonal and nonhormonal mechanisms. The proteins that mediate renal $\mathrm{P}_{\mathrm{i}}$ transport activity belong to a family of $\mathrm{Na}^{+} / \mathrm{P}_{\mathrm{i}}$ cotransporters that includes liver as well as kidney isoforms (Werner et al., 1991; Li and Xie, 1995). Interestingly, a sequence induced by subtoxic levels of NMDA in cerebellar granule cells also belongs to this family of transport proteins $(\mathrm{Ni}$ et al., 1994). Analysis of the mRNA shows that the expression of this sequence is restricted to the brain and, in particular, to neurons (Ni et al., 1994). Injection of mRNA for this brainspecific $\mathrm{Na}^{+}$-dependent $\mathrm{P}_{\mathrm{i}}$ transporter (BNPI) into Xenopus oocytes confirms that BNPI transports $\mathrm{P}_{\mathrm{i}}$ in a $\mathrm{Na}^{+}$-dependent manner (Ni et al., 1994). BNPI therefore may contribute to the $\mathrm{Na}^{+}$-dependent $\mathrm{P}_{\mathrm{i}}$ transport activity observed in cultured primary cortical neurons, cerebellar granule cells, and synaptosomes prepared from rat brain (Glinn et al., 1995; Furman et al., 1997).

Although $\mathrm{Na}^{+}$-dependent $\mathrm{P}_{\mathrm{i}}$ uptake may act simply to replenish ATP stores, a function that presumably would be required for all neuronal populations, in situ hybridization indicates that the expression of BNPI mRNA is restricted to a subset of neurons, including cortical cells, hippocampal pyramidal cells, granule cells of the dentate gyrus, and cerebellar granule cells (Ni et al., 1995), neurons that all use glutamate as a neurotransmitter. This restricted pattern of BNPI mRNA expression supports a function for BNPI specific to glutamatergic neurons. Moreover, BNPI shows strong sequence similarity to EAT-4, a Caenorhabditis elegans protein that appears to have a specific presynaptic role in 
glutamatergic transmission (Avery, 1993; Dent et al., 1997; Li et al., 1997; R. Y. N. Lee, E. R. Sawin, M. Chalfie, H. R. Horvitz, and L. Avery, unpublished observations).

To assess the physiological role of BNPI, we have generated a polyclonal antibody to the protein and used it to determine the location of the transporter in the rat brain. At the light microscopic level, immunocytochemistry shows that BNPI localizes to nerve terminals that release glutamate as a neurotransmitter. Consistent with a role for BNPI in excitatory transmission, electron microscopic immunolabeling shows that BNPI localizes predominantly to axon terminals at asymmetric synapses. The results thus provide anatomical evidence of a specific presynaptic role for BNPI in glutamatergic transmission, as suggested by the phenotype of eat-4 mutants. Further, although the $\mathrm{Na}^{+}$dependence of BNPI suggests that BNPI functions at the plasma membrane, electron microscopic immunolabeling indicates that the majority of BNPI resides on synaptic vesicles. Biochemical analysis by differential centrif ugation and velocity gradient fractionation confirms this localization, raising the possibility that exocytosis induced by neural activity may regulate BNPI function at the plasma membrane.

\section{MATERIALS AND METHODS}

BNPI-pGEX-3X plasmid construction and expression. The pGEX bacterial expression system (Pharmacia Biotech, Alameda, CA) was used to produce a glutathione $S$-transferase (GST) fusion protein containing the last 68 amino acids (residues 493-560) of rat BNPI (Ni et al., 1994). First, the $3^{\prime}$ end of the protein coding region (nucleotides 1600-1806) was amplified from BNPI cDNA, using PCR and primers (5'CGCGGATCCTGGAGAAACAGCCGTGGGCAGAGand5'-CGGAATTCTCAGTAGTCCCGGACAGGGGGTGG) engineered to contain $B a m \mathrm{HI}$ and EcoRI sites that facilitate subcloning into pGEX-3X. To produce the fusion protein, we induced Escherichia coli expressing the recombinant plasmid with isopropyl $\beta$-D-thiogalactoside (IPTG) for $\sim 4$ $\mathrm{hr}$ at room temperature (RT) and then sonicated it. The fusion protein was purified by chromatography over glutathione Sepharose (Pharmacia Biotech).

Polyclonal antibody production. Two female New Zealand white rabbits were immunized with the GST-BNPI fusion protein. First, the animals were inoculated intradermally with $\sim 200 \mu \mathrm{g}$ of fusion protein emulsified in Freund's complete adjuvant, and then they were boosted 4 weeks later by a subcutaneous injection of $\sim 100 \mu \mathrm{g}$ of fusion protein emulsified in Freund's incomplete adjuvant. Blood was obtained 9 and $14 \mathrm{~d}$ after the boost. The serum was adsorbed with rat liver acetone powder (LAP; Cappel, Organon Teknika, West Chester, PA) to reduce nonspecific immunoreactivity.

Cell transfection and membrane preparation. Rat BNPI cDNA in pcDNA I/Amp (Invitrogen, San Diego, CA) was transfected into COS1 cells by electroporation (Finn and Edwards, 1997). Briefly, COS1 cells grown in DMEM containing 10\% Cosmic calf serum (HyClone Laboratories, Logan, UT) were harvested and then electroporated at $0.4 \mathrm{kV}$ and $960 \mu \mathrm{F}$ with $15 \mu \mathrm{g}$ of DNA. At $3 \mathrm{~d}$ after electroporation the transfected COS cells were harvested, resuspended in $200 \mu \mathrm{l}$ of buffer A [(in mM) $150 \mathrm{NaCl}, 50$ Tris-HCl, 5 EGTA, and 10 EDTA, pH 7.4 on ice] containing protease inhibitors [(in $\mu \mathrm{g} / \mathrm{ml}) 1$ E64, 2 leupeptin, 2 pepstatin, 20 PMSF], and disrupted in a water bath sonicator. Cell debris was removed by sedimentation at $1300 \times g$ for $5 \mathrm{~min}$ at $4^{\circ} \mathrm{C}$.

Western analysis. Equal amounts of protein were loaded into each lane, except in the case of velocity sedimentation through glycerol, in which case equal volumes from each fraction were loaded. In all cases the proteins were separated by electrophoresis via $10 \%$ SDS-polyacrylamide and transferred to nitrocellulose. The nitrocellulose membranes were blocked in PBS containing 0.1\% Tween-20 and 5\% nonfat dry milk and then incubated with the relevant primary antibody in PBS containing $0.1 \%$ Tween-20 and $1 \%$ nonfat dry milk (PBS-TM) for $2 \mathrm{hr}$ at RT or overnight at $4^{\circ} \mathrm{C}$. BNPI was detected with a 1:2000 dilution of the C-terminal polyclonal antibody preadsorbed with LAP. Synaptophysin was detected with a monoclonal antibody (clone SVP-38; Sigma, St. Louis, MO) at a dilution of 1:5000, syntaxin with a monoclonal antibody (clone HPC-1; Sigma) at 1:2000, and the $\mathrm{Na}^{+} / \mathrm{K}^{+}$ATPase $\alpha_{1}$ subunit with a polyclonal antibody (Upstate Biotechnology, Lake Placid, NY) at 1:1000. After incubation with primary antibody the blots were washed three times in PBS-TM, incubated for $45 \mathrm{~min}$ in PBS-TM containing a 1:2000 dilution of the appropriate secondary antibody conjugated to horseradish peroxidase (Amersham, Arlington Heights, IL), and washed in PBS containing $0.1 \%$ Tween-20. The deposits were detected by enhanced chemiluminescence (Pierce, Rockford, IL).

Preparation of brain extracts. The brains of adult male Sprague Dawley rats were removed after decapitation and homogenized for 10 strokes at $\sim 750 \mathrm{rpm}$ in cold buffer B [(in mM) 50 Tris-HCl, pH 7.4, 5 EGTA, and 10 EDTA] containing protease inhibitors [(in $\mu \mathrm{g} / \mathrm{ml}) 2$ aprotinin, 1 E64, 2 leupeptin, 2 pepstatin, and 20 PMSF] by using a Wheaton glass/Teflon homogenizer (clearance 0.1-0.15 mm; Fisher Scientific, Santa Clara, CA). Cell debris was removed from this homogenate by centrifugation at $1075 \times g_{\max }$ in a Sorvall SS34 rotor (DuPont, Newtown, CT) for $20 \mathrm{~min}$ at $4^{\circ} \mathrm{C}$ and was resuspended in buffer $\mathrm{B}$ with protease inhibitors to yield the pellet P1. The postnuclear supernatant (PNS) was sedimented at $152,000 \times g_{\max }$ in an SW41 rotor (Beckman, Palo Alto, CA) for $1 \mathrm{hr}$ at $4^{\circ} \mathrm{C}$. After the addition of protease inhibitors the resulting high-speed supernatant (HSS1) was centrifuged again under the same conditions to ensure the removal of all membranes from the supernatant. The resulting second high-speed supernatant (HSS2) also was supplemented with protease inhibitors. The high-speed pellets from both centrifugations were resuspended in buffer B with protease inhibitors and pooled to yield a high-speed pellet fraction (HSP).

Preparation of kidney extracts. The kidneys were removed from an adult male Sprague Dawley rat, frozen on liquid nitrogen, and crushed to a fine powder on dry ice. After its addition to $0.32 \mathrm{M}$ sucrose and $10 \mathrm{~mm}$ HEPES, pH 7.4 [containing $5 \mathrm{~mm}$ Mg-EGTA, $0.4 \mu \mathrm{M}$ diisopropylfluorophosphate (DFP), and (in $\mu \mathrm{g} / \mathrm{ml}$ ) 2 aprotinin, 2 E64, 5 leupeptin, and 2 pepstatin], the mixture was homogenized at $\sim 750 \mathrm{rpm}$ for 12 strokes in a Wheaton glass/Teflon homogenizer (clearance 0.1-0.15 mm; Fisher Scientific), and the cell debris was removed by centrifugation at $1600 \times$ $g$ for $10 \mathrm{~min}$ at $4^{\circ} \mathrm{C}$.

Synaptosome preparation. Synaptosomes were prepared by standard methods (Huttner et al., 1983) with minor modifications. Briefly, the cerebral cortices of male Sprague Dawley rats were homogenized in cold buffer C (0.32 M sucrose, 4 mM HEPES-NaOH, pH 7.4, and 1 mM EGTA) containing protease inhibitors [(in $\mu \mathrm{g} / \mathrm{ml}) 2$ aprotinin, 1 E64, 2 leupeptin, 2 pepstatin, and $20 \mathrm{PMSF}$ ] by 10 strokes at $900 \mathrm{rpm}$ in a Kontes number 22 glass/Teflon homogenizer (clearance $0.13-0.18 \mathrm{~mm}$; Fisher Scientific) at $4^{\circ} \mathrm{C}$. The homogenate was centrifuged in an SS34 rotor (DuPont) for 10 min at $1000 \times g_{\max }$ to yield a pellet (P1) and a supernatant (S1). P1 was resuspended in buffer $\mathrm{C}$ with protease inhibitors and EGTA. Then S1 was centrifuged at $12,000 \times g_{\max }$ in an SS34 rotor for $15 \mathrm{~min}$. The resulting supernatant (S2) was removed. The pellet (P2) was washed by being resuspended in buffer $\mathrm{C}$ containing protease inhibitors and then was centrifuged at $14,500 \times g_{\max }$ for 15 min to yield a supernatant (S2') and pellet $\left(\mathrm{P} 2^{\prime}\right)$. $\mathrm{P} 2^{\prime}$, the crude synaptosomal fraction, was resuspended in buffer $\mathrm{C}$ containing protease inhibitors, transferred to a Kontes number 22 glass/Teflon homogenizer (clearance $0.13-0.18 \mathrm{~mm}$ ), mixed by inversion with $9 \mathrm{vol}$ of cold water containing $1 \mathrm{~mm}$ EGTA and protease inhibitors, and immediately disrupted by three strokes of homogenization at $3000 \mathrm{rpm}$. HEPES-NaOH, pH 7.4, was added to a final concentration of $8.5 \mathrm{~mm}$, and the mixture was centrifuged at $33,000 \times g_{\max }$ in an SS34 rotor for $20 \mathrm{~min}$ to yield a lysate pellet (LP1) and lysate supernatant (LS1). LP1 was resuspended in a 1:10 dilution of buffer $\mathrm{C}$ containing protease inhibitors and HEPES-NaOH, $\mathrm{pH} 7.4$ (final concentration 8.5 $\mathrm{mM}$ ). Protease inhibitors then were added to LS1, and this fraction was centrifuged at $251,500 \times g_{\max }$ in a $70.1 \mathrm{Ti}$ rotor (Beckman) for $2 \mathrm{hr}$ to yield a supernatant (LS2) and pellet (LP2). LP2 was resuspended in 40 mM sucrose containing $1 \mathrm{~mm}$ EGTA and protease inhibitors.

Glycerol velocity sedimentation. Velocity sedimentation through glycerol was performed by the procedure of Clift-O'Grady et al. (1990) with minor modifications. Glycerol gradients $(5-25 \%)$ were prepared in (in mM) 10 HEPES-NaOH, pH 7.4, $150 \mathrm{NaCl}, 1$ EGTA, and $0.1 \mathrm{MgCl}_{2}$ with protease inhibitors [(in $\mu \mathrm{g} / \mathrm{ml}) 2$ aprotinin, 1 E64, 2 leupeptin, 2 pepstatin, and $20 \mathrm{PMSF}]$ over a pad of $2 \mathrm{M}$ sucrose. LS1 samples $(\sim 130 \mu \mathrm{g})$, containing intraterminal components such as synaptic vesicles (Huttner et al., 1983), were layered onto the glycerol gradients and centrifuged at $195,600 \times g_{\max }$ in an SW 50.1 rotor (Beckman) for $1 \mathrm{hr}$ at $5^{\circ} \mathrm{C}$. Fractions were collected from the top of the gradient.

Immunohistochemistry. Adult male Sprague Dawley rats were anesthetized and perfused with PBS, followed by $4 \%$ paraformaldehyde in PBS. The brains were dissected, immersed in the same fixative overnight at 
$4^{\circ} \mathrm{C}$, cryoprotected in $30 \%$ sucrose at $4^{\circ} \mathrm{C}$, and sectioned at $40 \mu \mathrm{m}$ on a freezing microtome. Floating brain sections were incubated in PBS containing $1 \%$ normal goat serum (NGS) and $0.3 \%$ Triton $\mathrm{X}-100$ (wash buffer) for $30 \mathrm{~min}$, rinsed, incubated in PBS containing $0.3 \% \mathrm{H}_{2} \mathrm{O}_{2}$ for 30 min, rinsed, blocked for $1.5 \mathrm{hr}$ in PBS containing 3\% NGS and $0.3 \%$ Triton X-100, and incubated overnight at $4^{\circ} \mathrm{C}$ in wash buffer containing a 1:2000 dilution of primary BNPI antibody preadsorbed with LAP. To confirm the specificity of the reaction, we included $10 \mu \mathrm{g}$ of either GST-BNPI or the control fusion protein GST-VGAT (Chaudhry et al., 1998) in the preadsorption of the BNPI antiserum with LAP. The sections were washed, incubated for $30 \mathrm{~min}$ at RT with biotinylated goat anti-rabbit secondary antibody (Vector, Burlingame, CA) diluted 1:200, washed again, and incubated in a 1:400 dilution of avidin-biotin complex conjugated to horseradish peroxidase (Vector) for $30 \mathrm{~min}$. After being washed, the peroxidase reaction was visualized with 3,3'diaminobenzidine and $\mathrm{H}_{2} \mathrm{O}_{2}$ and $0.27 \% \mathrm{NiSO}_{4}$ to enhance the reaction. Sections were dehydrated in graded ethanols and xylene and then coverslipped with Permount (Fisher Scientific).

Electron microscopy. The methods for tissue preparation and immunocytochemical labeling were based on those of Leranth and Pickel (1989). Adult male Sprague Dawley rats were anesthetized with sodium pentobarbital (50 mg/kg, i.p.) and perfused in rapid succession with (1) $10 \mathrm{ml}$ of phosphate buffer (PB), pH 7.4, containing $1000 \mathrm{U} / \mathrm{ml}$ heparin and 0.15 $\mathrm{M} \mathrm{NaCl}$; (2) $50 \mathrm{ml}$ of $3.75 \%$ acrolein and $2 \%$ paraformaldehyde in $\mathrm{PB}$; and (3) $200 \mathrm{ml}$ of $2 \%$ paraformaldehyde in PB. The brains were removed and post-fixed in $2 \%$ paraformaldehyde for $30 \mathrm{~min}$ and then sectioned at $40 \mu \mathrm{m}$ coronal sections with a Lancer Vibratome. Sections of tissue through forebrain regions were incubated for $30 \mathrm{~min}$ in PB containing $1 \%$ sodium borohydride. Then all sections were cryoprotected for $15 \mathrm{~min}$ in $0.05 \mathrm{M}$ PB containing $25 \%$ sucrose and $3.5 \%$ glycerol, rapidly frozen in chlorodifluoromethane followed by liquid nitrogen, and thawed in PB at RT. The free-floating tissue sections were incubated overnight at RT in $0.1 \%$ bovine serum albumin (BSA)-Tris saline (TS; $0.9 \% \mathrm{NaCl}$ in $0.1 \mathrm{M}$ Tris, pH 7.6) with BNPI C-terminal antiserum diluted 1:6000 for peroxidase and 1:3000 for immunogold labeling, respectively. In tissue that was prepared for peroxidase labeling, the sections were incubated for $30 \mathrm{~min}$ in biotinylated goat anti-rabbit immunoglobulin diluted $1: 400$ in $0.1 \%$ BSA, for $30 \mathrm{~min}$ in avidin-biotin peroxidase complex diluted 1:100, and then for $6 \mathrm{~min}$ in a solution containing $22 \mathrm{mg}$ of 3,3'-diaminobenzidine and $10 \mu \mathrm{l}$ of $30 \% \mathrm{H}_{2} \mathrm{O}_{2}$ in $100 \mathrm{ml}$ of $0.1 \mathrm{M}$ TS, pH 7.6. The sections used for silver-enhanced immunogold labeling (Chan et al., 1990) were incubated for $2 \mathrm{hr}$ in a 1:50 dilution of colloidal gold $(1 \mathrm{~nm})$ conjugated to anti-rabbit IgG (Amersham), fixed in PBS containing 2\% glutaraldehyde for $10 \mathrm{~min}$, and reacted with a silver solution by using a light stable intenSEM kit (Amersham) for 5-8 min. The immunolabeled tissue sections were fixed in $2 \%$ osmium tetroxide for $60 \mathrm{~min}$, dehydrated in a series of graded ethanols and propylene oxide, and flat-embedded in Embed 812 between two pieces of Aclar plastic.

Ultrathin sections were collected from the outer surface of the plasticembedded tissue with an LKB ultramicrotome. These were taken from three regions: the stratum lucidum of CA3, the polymorphic or hilar layer of the dentate gyrus in the dorsal hippocampus, and the dorsolateral caudate nucleus at the level of the crossing of the anterior commissure (Paxinos and Watson, 1986). The sections were counterstained with uranyl acetate and lead citrate and then examined with a Philips electron microscope (Mahwah, NJ).

Primary hippocampal cultures. Hippocampi from E19 Sprague Dawley rats were dissociated by trypsinization, and the cells were plated on poly-D-lysine-coated coverslips (12 mm in diameter) at a density of $\sim 300 / \mathrm{mm}^{2}$ in B27/Neurobasal medium (Brewer et al., 1993). After $14 \mathrm{~d}$ in vitro the coverslips were dipped in $\mathrm{PBS}$ with $\mathrm{Ca}^{2+}$ and $\mathrm{Mg}^{2+}$, fixed in $4 \%$ paraformaldehyde, washed in PBS, blocked in PBS containing 2\% BSA, $1 \%$ fish skin gelatin, and $0.02 \%$ saponin (blocking buffer) for $1.5 \mathrm{hr}$ at RT, and incubated at RT for $1.5 \mathrm{hr}$ or $4^{\circ} \mathrm{C}$ overnight in primary antibody diluted in blocking buffer. The primary antibodies included a monoclonal antibody to synaptophysin (clone SVP-38; Sigma) at a dilution of 1:100, as well as the C-terminal BNPI polyclonal antiserum at 1:2000, preadsorbed with LAP as described above. Then the coverslips were washed with blocking buffer and incubated for $1 \mathrm{hr}$ at RT in goat anti-mouse or goat anti-rabbit secondary antibodies conjugated to fluorescein-5-isothiocyanate (FITC) or tetramethyl rhodamine isothiocyanate fluorophores (ICN Biomedicals, Costa Mesa, CA) diluted 1:100 in blocking buffer. After three washes in blocking buffer (10 min each) followed by two brief washes in PBS, the coverslips were mounted with a
ProLong Antifade kit (Molecular Probes, Eugene, OR) and viewed by epifluorescence under oil at $63 \times$ magnification.

\section{RESULTS}

To determine the distribution of BNPI, we raised an antibody to a bacterial fusion protein containing the $\mathrm{C}$ terminus of the transporter. The antiserum recognizes a broad $\sim 60 \mathrm{kDa}$ band in COS cells transfected with rat BNPI cDNA, but not in control cells (Fig. $1 A$ ), consistent with the 560 residue protein predicted by the cDNA (Ni et al., 1994). In addition, the antibody recognizes a single broad $\sim 60 \mathrm{kDa}$ band in subcellular fractions of rat brain (Fig. $1 B$ ); confirming the specificity of the antibody, preadsorption with the GST fusion protein used as immunogen prevents the detection of this $\sim 60 \mathrm{kDa}$ species (Fig. $1 C$ ). An $\sim 85 \mathrm{kDa}$ immunoreactive species also occurs in both BNPI-transfected and control COS cells, but this background band does not occur in rat brain. COS cells transfected with the BNPI cDNA contain additional $\sim 175,52$, and $50 \mathrm{kDa}$ immunoreactive species that do not appear in control cells or in the brain, suggesting that these bands may result only from expression in a heterologous system. Consistent with the brain-specific expression of BNPI, rat kidney does not express the $\sim 60 \mathrm{kDa}$ immunoreactive species (Fig. $1 B$ ). As anticipated for an integral membrane protein, the $\sim 60 \mathrm{kDa}$ immunoreactive species in brain sediments with membranes in a highspeed pellet (HSP) rather than with soluble proteins in the highspeed supernatants (HSS1 and HSS2; Fig. 1B). Furthermore, the inability to pellet a large proportion of BNPI in the initial lowspeed centrifugation (P1) indicates that most of the transporter in the brain does not associate tightly with the cytoskeleton.

\section{Glutamatergic projections express BNPI}

With the use of light microscopy, immunocytochemistry shows the expression of BNPI protein in gray matter, including cortex and basal ganglia (Fig. $2 A, B$ ). White matter such as the corpus callosum shows no detectable labeling for BNPI, consistent with the exclusive expression of BNPI mRNA by neurons. The cortex does not show a laminar pattern of labeling, and both cortex and caudate putamen lack immunoreactive cell bodies. Within the neuropil of the cortex and caudate putamen nucleus, BNPI exhibits a punctate pattern of immunoreactivity suggestive of neuronal processes (Fig. 2C,D). Preadsorption of the antibody with the GST fusion protein used as immunogen completely abolishes the immunoreactivity in brain sections, confirming the specificity of the antibody (Fig. 2E).

Sections through the hippocampus show a distinctive laminar pattern of immunoreactivity (Fig. $3 A, B$ ). Dense immunoreactivity occurs in the polymorphic and molecular layers of both the dentate gyrus and the hippocampus proper. Examination of the CA3 region under higher magnification reveals coarse granular labeling at the periphery of the pyramidal cell layer (Fig. 3D) strongly suggestive of mossy fiber synapses (Haug et al., 1971; Amaral and Dent, 1981). Stratum oriens of CA3 exhibits weaker but still intense immunoreactivity that occurs in nerve terminallike puncta, and stratum radiatum of CA3 shows even less intense BNPI immunoreactivity (Fig. 3B,D). The results thus indicate the heterogeneity of BNPI expression at different excitatory connections. In CA1, strata oriens and radiatum also show diffuse granular labeling suggestive of BNPI localization to the terminals of Schaffer collaterals (Fig. $3 E$ ), and this labeling substantially exceeds the labeling observed in stratum lacunosum moleculare (Fig. 3B), further supporting the heterogeneity of BNPI expression. In the dentate gyrus the outer two-thirds of the molecular 

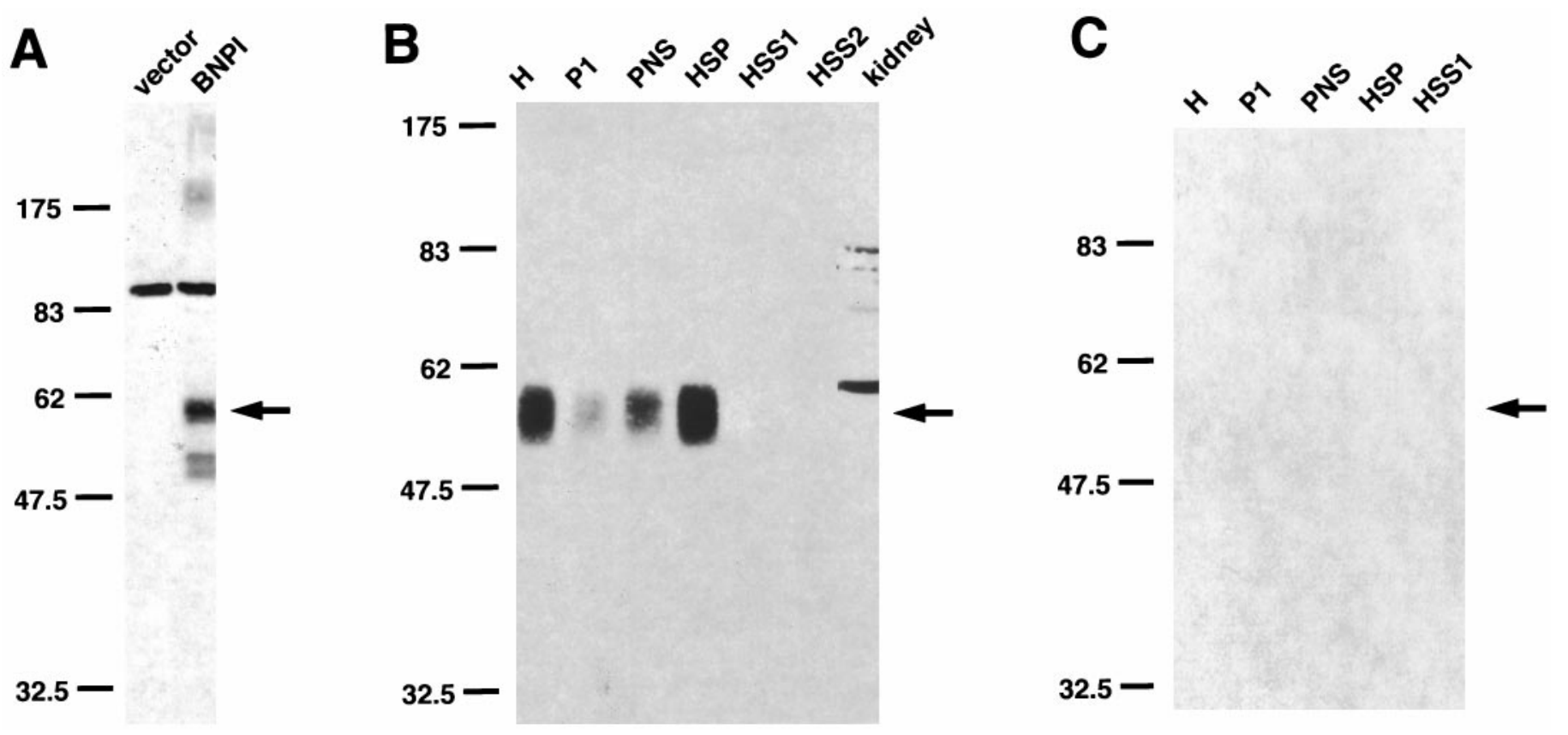

Figure 1. BNPI antiserum specifically recognizes a $60 \mathrm{kDa}$ protein in transfected COS cells and rat brain. $A$, COS cells were transfected with rat BNPI cDNA or with vector alone. Equal amounts of protein from each postnuclear supernatant were separated by electrophoresis via $10 \%$ SDSpolyacrylamide, transferred to nitrocellulose, and immunoblotted with antiserum generated against the $\mathrm{C}$ terminus of BNPI. The antiserum recognizes a single broad $\sim 60 \mathrm{kDa}$ band in COS cells expressing BNPI (arrow), but not in control cells. Note that the $\sim 85 \mathrm{kDa}$ background species detected in both BNPI-transfected and control cells, as well as the faint $\sim 175,52$, and $50 \mathrm{kDa}$ species present only in BNPI-transfected cells, does not occur in the brain. $B$, BNPI antiserum recognizes a single $\sim 60 \mathrm{kDa}$ species in rat brain (arrow). Differential centrifugation of rat brain extracts was performed as described in Materials and Methods, and a Western blot containing equal amounts of protein from each fraction was immunolabeled by using the BNPI $\mathrm{C}$-terminal antiserum preadsorbed with a control GST fusion protein. The homogenate $(H)$ contains an $\sim 60 \mathrm{kDa}$ immunoreactive species. Low-speed centrifugation $(1075 \times g$ for $20 \mathrm{~min})$ to remove cell debris $(P 1)$ results in the sedimentation of some immunoreactive material, but the majority occurs in the postnuclear supernatant $(P N S)$. Centrifugation of the $P N S$ at $152,000 \times g_{\max }$ for $1 \mathrm{hr}$ sediments BNPI in the high-speed pellet (HSP), whereas the high-speed supernatants (HSS1 and HSS2) contain little immunoreactive material. Postnuclear supernatant from the rat kidney (40 $\mu \mathrm{g}$ of protein) does not express the $\sim 60 \mathrm{kDa}$ species, consistent with the brain-specific expression of BNPI. The molecular weights of standards (in kilodaltons) are shown to the left. $C$, Preadsorption of the BNPI antiserum with the GST fusion protein used as an immunogen prevents detection of the $\sim 60 \mathrm{kDa}$ species (arrow) in the same rat brain fractions that were used in $B$.

layer label more strongly for BNPI than does the inner one-third (Fig. 3B), indicating preferential localization to the perforant path inputs from the entorhinal cortex relative to inputs from the ipsilateral associational/commissural projection (Matthews et al., 1976; Johnston and Amaral, 1998). Similar to cell bodies in the cortex and striatum, cell bodies in the hippocampus, including hippocampal pyramidal cells, dentate gyrus granule cells, and hilar interneurons, show no detectable BNPI immunoreactivity (Fig. 3B,D,E). Considered as a whole, the distribution of BNPI immunoreactivity in the hippocampus strongly resembles that for glutamate, suggesting the preferential expression of BNPI at excitatory synapses (Storm-Mathisen et al., 1983).

Sections through the midbrain and rostral pons show immunoreactivity for BNPI in gray matter such as the periaqueductal gray and pontine nuclei (Fig. 4A). White matter such as the corticospinal tracts (in the cerebral peduncle), the decussation of the superior cerebellar peduncle, the lateral lemnisci, and the lateral tegmental tracts shows no labeling. Similar to other brain regions, BNPI is not detectable in cell bodies of the substantia nigra and tectum (Fig. $4 B, D$ ). Rather, BNPI immunoreactivity is distributed uniformly in terminal-like puncta throughout both regions.

In the cerebellum, BNPI immunoreactivity has a laminar distribution (Fig. $5 A, B$ ). The molecular layer shows dense punctate labeling suggestive of localization to climbing or parallel fibers that synapse onto Purkinje cell dendrites (Fig. 5D). Within the granule cell layer, BNPI immunoreactivity appears much less dense but has a punctate appearance similar to that observed in the molecular layer. These large punctate structures strongly resemble the rosettes formed by excitatory mossy fiber terminals on granule cells (Palay and Chan-Palay, 1974; Llinás and Walton, 1998). The pattern of labeling does not resemble that observed for inhibitory connections made by GABAergic cells (Esclapez et al., 1994; Chaudhry et al., 1998), further supporting the specific localization of BNPI to excitatory terminals. As in other brain regions, cell bodies in the cerebellum, including granule and Golgi cells of the granule layer, basket and stellate cells of the molecular layer, and Purkinje cells, show no immunoreactivity for BNPI (Fig. 5D).

\section{BNPI localizes to nerve terminals in hippocampal cultures}

To determine whether BNPI localizes to nerve terminals, we immunolabeled 2-week-old primary hippocampal cultures with antibodies to both BNPI and the synaptic vesicle marker synaptophysin (Jahn et al., 1985). Similar to synaptophysin (Fig. 6A,C), BNPI distributes in a punctate pattern along neuronal processes within the cultures (Fig. $6 B, D$ ). Double labeling confirms that BNPI colocalizes with synaptophysin (Fig. 6). However, many varicosities that contain synaptophysin lack detectable BNPI, indicating that BNPI localizes only to a subset of nerve terminals. Some neuronal cell bodies also stain weakly for BNPI, and all of these cell bodies stain for the phosphate-activated glutaminase, PAG (data not shown), a protein highly expressed in many 

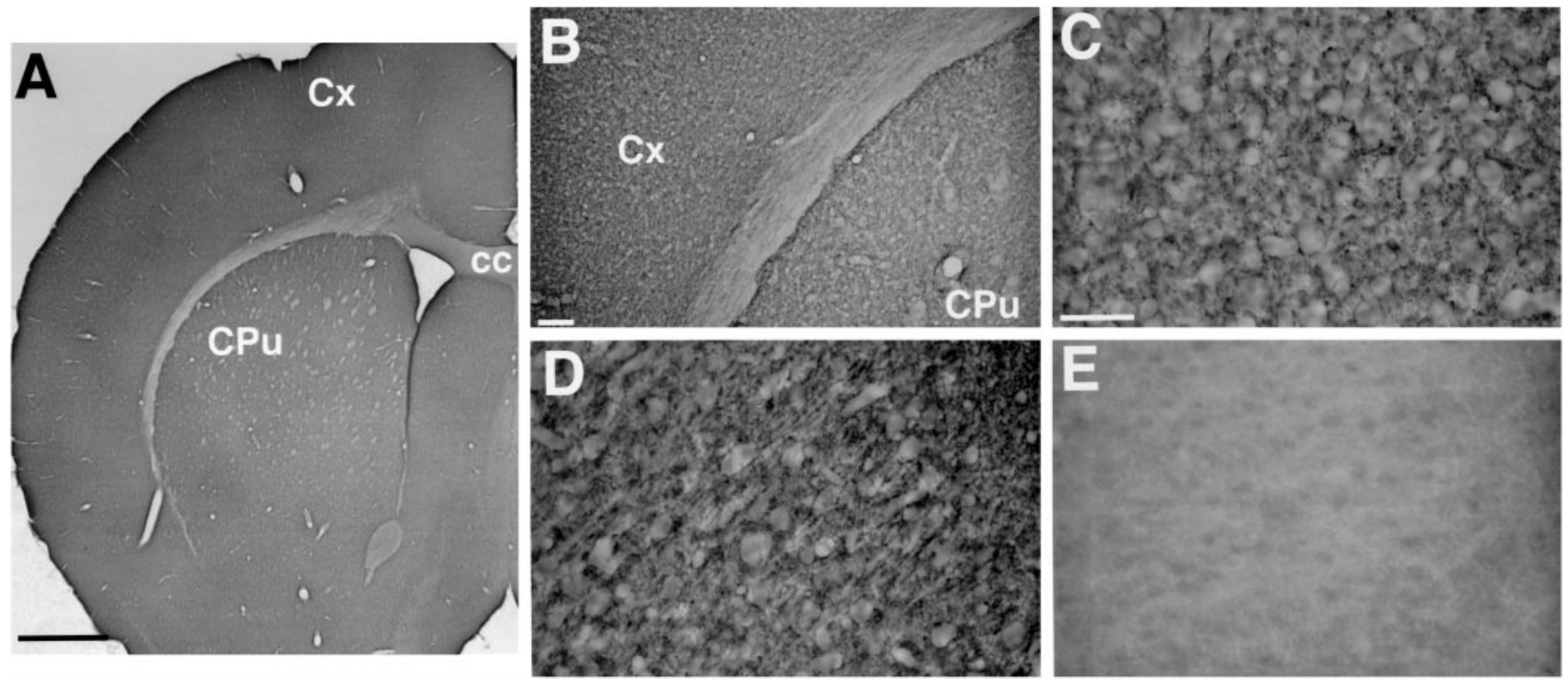

Figure 2. BNPI immunohistochemistry at the level of the basal ganglia. Representative $40 \mu \mathrm{m}$ coronal sections from rat brain were immunolabeled for BNPI by using the antiserum preadsorbed with LAP and either the control GST fusion protein GST-VGAT $(A-D)$ or GST-BNPI as a control ( $E)$. $A$, $B$, Sections through the basal ganglia show immunoreactivity distributed diff usely throughout the cortex $(C x)$ and caudate putamen $(C P u)$. The cortex lacks a laminar pattern of immunoreactivity. White matter such as the corpus callosum $(c c)$ shows little labeling. $C, D$, At high magnification, punctate immunoreactivity occurs in nerve fibers within caudate putamen $(C)$ and cortex $(D)$. Cell bodies show no labeling. $E$, Adsorption of the antibody with GST-BNPI abolishes immunolabeling (shown here for cortex), confirming the specificity of the reaction. Scale bars: $A, 1 \mathrm{~mm} ; B, 100 \mu \mathrm{m} ; C-E, 50 \mu \mathrm{m}$.
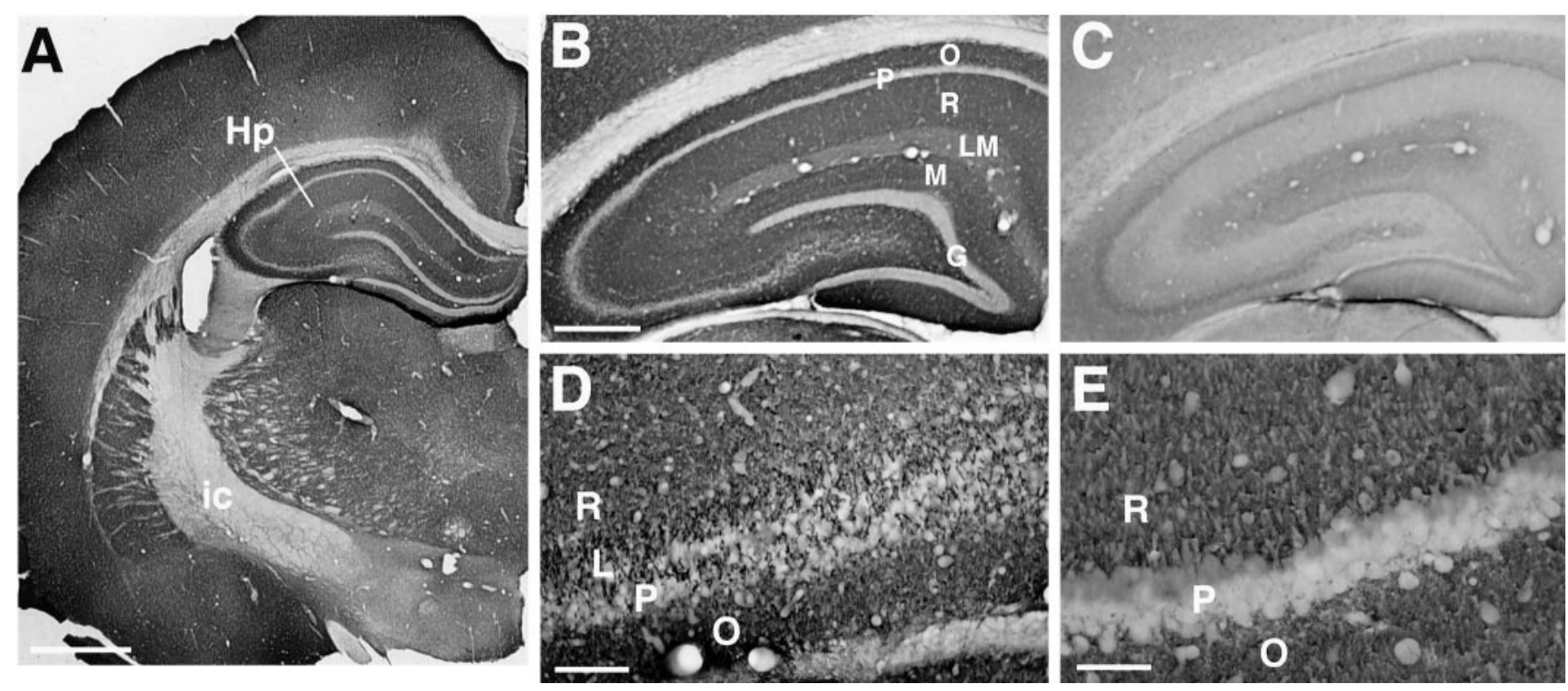

Figure 3. BNPI immunohistochemistry at the level of the hippocampus. Representative $40 \mu \mathrm{m}$ coronal sections from rat brain were immunolabeled for BNPI by using the antiserum preadsorbed with LAP and either the control GST fusion protein GST-VGAT $(A, B, D, E)$ or GST-BNPI as a control ( $C$ ). $A$, A section through the hippocampus $(H p)$ shows a distinctive pattern of immunoreactivity, particularly within the molecular and polymorphic layers of the hippocampus. White matter such as the internal capsule $(i c)$ shows little labeling. $B$, Under higher magnification the hippocampus shows dense immunoreactivity in stratum oriens $(O)$ and stratum radiatum $(R)$, with a marked reduction in labeling in stratum lacunosum moleculare $(L M)$. In the dentate gyrus the outer two-thirds of the molecular layer $(M)$ label more strongly for BNPI than the inner one-third, suggesting preferential localization to excitatory perforant path inputs from the entorhinal cortex. Strikingly, the granule cell body layer of the dentate gyrus $(G)$ and the pyramidal cell body layer $(P)$ of the hippocampus proper both lack substantial immunoreactivity. $C$, Adsorption of the antibody with GST-BNPI abolishes the immunolabeling, confirming the specificity of the reaction. $D, E$, A high-magnification view of CA3 $(D)$ shows coarse granular labeling in stratum lucidum $(L)$ at the periphery of the pyramidal cell layer $(P)$, strongly suggestive of mossy fiber synapses. Stratum oriens $(O)$ and stratum radiatum $(R)$ of both CA3 $(D)$ and CA1 $(E)$ show weaker, more diffuse BNPI immunoreactivity. Scale bars: $A, 1 \mathrm{~mm} ; B, C, 500 \mu \mathrm{m} ; D, 100 \mu \mathrm{m} ; E, 50 \mu \mathrm{m}$. 

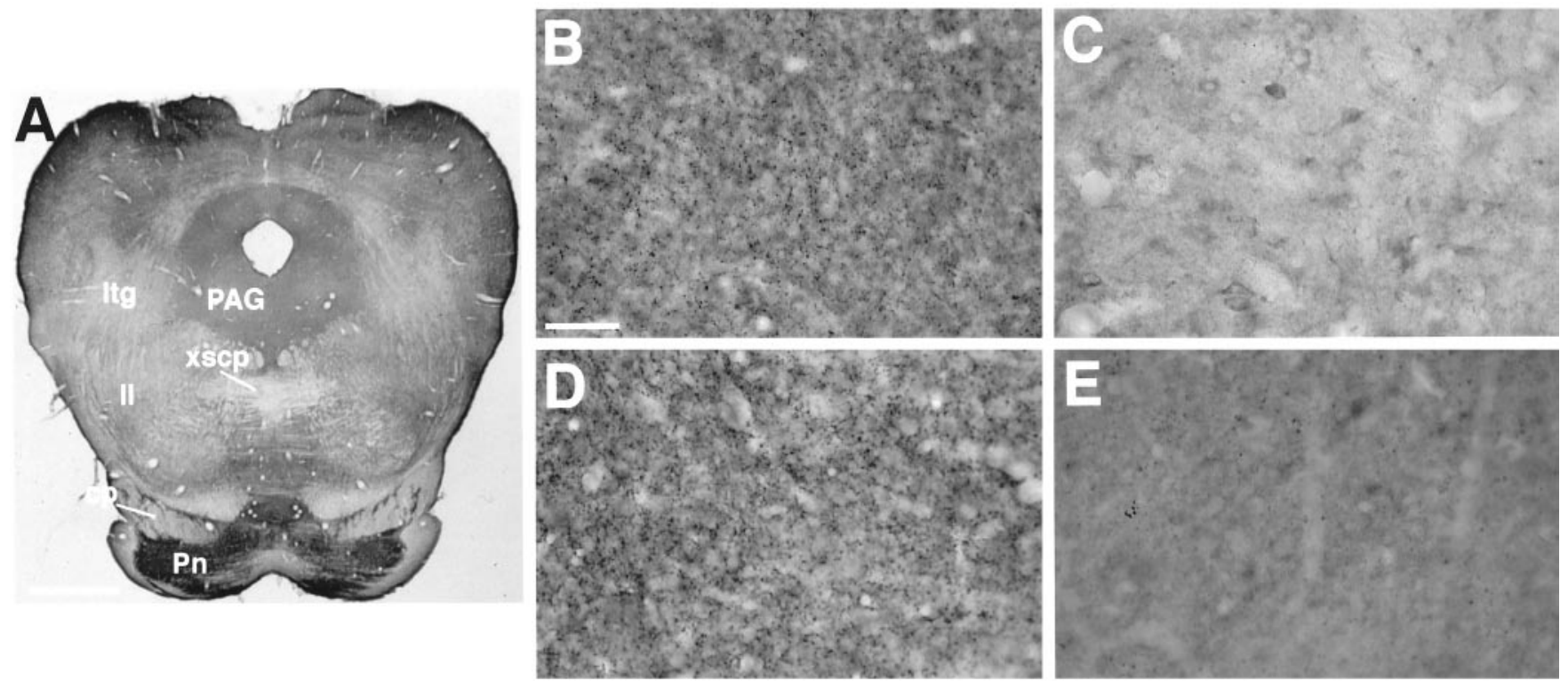

Figure 4. BNPI immunohistochemistry at the level of the caudal midbrain. Representative $40 \mu \mathrm{m}$ coronal sections from rat brain were immunolabeled for BNPI by using the antiserum preadsorbed with LAP and either the control GST fusion protein GST-VGAT $(A, B, D)$ or GST-BNPI as a control $(C, E) . A$, A section through the rostral pons shows immunoreactivity in gray matter of the periaqueductal gray $(P A G)$ and particularly strong labeling in the pontine nuclei $(P n)$. White matter such as the corticospinal tracts in the cerebral peduncle $(c p)$, the decussation of the superior cerebellar peduncle $(x s c p)$, the lateral lemnisci $(l l)$, and the lateral tegmental tracts (ltg) shows little labeling. $B, D$, Sections through the midbrain observed under high magnification show uniform punctate immunoreactivity in the neuropil of the substantia nigra $(B)$ and tectum $(D)$. Cell bodies in both regions show no labeling. $C, E$, Adsorption of the antibody with GST-BNPI abolishes the majority of punctate immunoreactivity in the substantia nigra $(C)$ and tectum $(E)$, confirming the specificity of the reaction. Scale bars: $A, 1 \mathrm{~mm} ; B-E, 50 \mu \mathrm{m}$.

glutamatergic neurons (Najlerahim et al., 1990; Aoki et al., 1991; Kaneko and Mizuno, 1994; Torgner et al., 1998).

\section{Localization of BNPI to synaptic vesicles at excitatory synapses}

To determine the subcellular localization of BNPI, we used electron microscopic immunolabeling. As a confirmation of the light microscopic analysis of the hippocampus, electron microscopic immunoperoxidase labeling in stratum lucidum of CA3 shows prominent reaction product in large axon terminals having the morphological characteristics of mossy fiber boutons (Fig. 7A) (Amaral and Dent, 1981). In the hilar layer of the dentate gyrus, where mossy fiber collaterals terminate, a few large terminals similar to those in the CA3 region contain BNPI immunoreactivity (data not shown). Many smaller terminals in the dentate gyrus that form asymmetric excitatory-type synapses with dendritic spines also label for BNPI (Fig. 7B). Thus, except for rare dendritic spines and isolated glial processes, BNPI localizes exclusively to axon terminals.

Nerve terminals in the hippocampus show heterogeneous expression of BNPI. In processes in which membrane specializations are observed, the labeled terminals form asymmetric synapses with unlabeled dendritic spines (Fig. $7 B$ ). Symmetric synapses do not contain detectable BNPI (data not shown), supporting a specific role for the protein in excitatory transmission. In addition, many terminals forming asymmetric synapses do not contain detectable BNPI, indicating expression only at a subset of excitatory synapses (Fig. $7 B$ ). Within the labeled terminals the peroxidase reaction product distributes diffusely along the membranes of small synaptic vesicles (Fig. $7 A, B$ ). Intense reaction product also associates with the dense core vesicles found in mossy fiber terminals of CA3 (Fig. 7A) and in terminals within the hilar region of the dentate gyrus (Fig. 7B). BNPI therefore appears to localize to specialized secretory vesicles within a subset of excitatory nerve terminals.

We also have used electron microscopic immunoperoxidase labeling to examine the distribution of BNPI in the dorsal caudate putamen nuclei (Fig. 7C). Reaction product densely distributes to nerve terminals and small unmyelinated axons adjacent to other unlabeled processes. As in the hippocampus the terminals forming asymmetric synapses show intense labeling, but symmetric synapses contain no reaction product (data not shown). Within the labeled nerve terminals and axons, BNPI immunoreactivity surrounds the membranes of small vesicles (Fig. 7C).

Because the immunoperoxidase method cannot resolve the precise subcellular location of BNPI, we used electron microscopic labeling with immunogold-silver (Fig. 8). Similar to the peroxidase reaction product, silver-intensified immunogold particles localize to nerve terminals only at asymmetric synapses in the caudate putamen. However, not all terminals forming asymmetric synapses were labeled, and some of these unlabeled terminals form asymmetric synapses onto the same dendrites that receive input from BNPI-labeled terminals. Within the labeled terminals, BNPI localizes to the membrane of small synaptic vesicles. The labeling appears more intense over synaptic vesicles distant from the active zone, although we did not evaluate this rigorously. In addition, a few gold particles directly contact the plasma membrane, but only in the vicinity of synaptic vesicles at regions of the terminal distant from the active zone. Therefore, despite the $\mathrm{Na}^{+}$ dependence of BNPI activity, BNPI localizes predominantly to synaptic vesicles at asymmetric excitatory-type synapses.

\section{Biochemical fractionation demonstrates BNPI on synaptic vesicles}

Because either the tissue preparation required for immunoelectron microscopy or the interaction of BNPI with another protein 

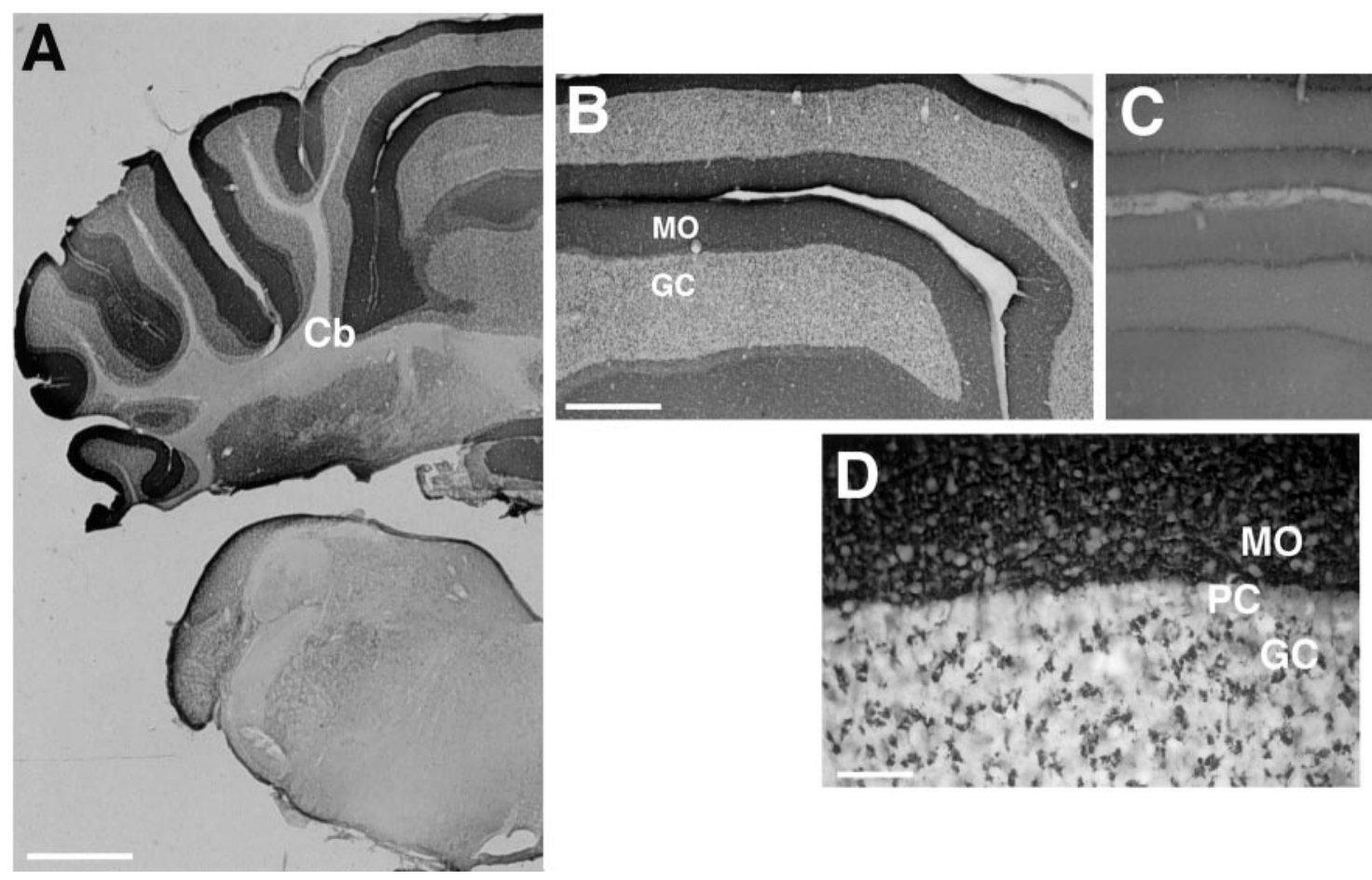

Figure 5. BNPI immunohistochemistry at the level of the medulla and cerebellum. Representative $40 \mu \mathrm{m}$ coronal sections from rat brain were immunolabeled for BNPI by using the antiserum preadsorbed with LAP and either the control GST fusion protein GST-VGAT $(A, B, D)$ or GST-BNPI as a control $(C)$. A, A section through the cerebellum $(C b)$ shows prominent immunoreactivity in cerebellar cortex. $B$, A high-magnification view of the cerebellar cortex reveals strong dense labeling in the molecular layer $(M O)$ and lighter labeling in the granule cell layer $(G C)$. $C$, Adsorption of the antibody with GST-BNPI abolishes the immunolabeling, confirming the specificity of the reaction. $D$, At high magnification the granule cell layer (GC) shows large punctate structures characteristic of mossy fiber synapses onto granule cells. Within the molecular layer $(M O)$ the immunoreactivity produces a dense coarse labeling pattern suggestive of climbing or parallel fiber synapses onto Purkinje cell dendrites. Cell bodies, including Purkinje cells $(P C)$, granule and Golgi cells, and basket and stellate cells, show no immunoreactivity. Scale bars: $A, 1 \mathrm{~mm} ; B, C, 500 \mu \mathrm{m} ; D, 50 \mu \mathrm{m}$.

may limit the access of BNPI antibody at sites such as the plasma membrane, we also examined the distribution of the transporter, using biochemical methods. Biochemical fractionation followed by immunoblot analysis obviates problems related to fixation or protein interaction and hence may identify plasma membrane BNPI not detectable by immunoelectron microscopy.

To distinguish synaptic vesicles from plasma membrane, we first prepared synaptosomes from the rat cortex. BNPI initially sediments with plasma membrane proteins such as the $\mathrm{Na}^{+} / \mathrm{K}^{+}$ ATPase and syntaxin (Bennett et al., 1993) in the insoluble debris (P1) and in the crude synaptosomal pellets, $\mathrm{P} 2$ and P2' (Fig. 9A). However, the synaptic vesicle protein synaptophysin also appears in these same fractions. After hypo-osmotic lysis of the synaptosomes, $\mathrm{Na}^{+} / \mathrm{K}^{+}$ATPase and syntaxin sediment with the heavy lysed synaptosomal membranes (LP1), whereas BNPI and synaptophysin fractionate together into the lighter membrane fractions, LS1 and LP2 (Fig. 9A). Thus, BNPI cofractionates with synaptic vesicles by differential centrifugation.

Velocity sedimentation through glycerol separates synaptic vesicles from essentially all other membranous organelles (CliftO'Grady et al., 1990). We used LS1 as the starting material because it contains synaptic vesicles (Fig. 9A), and sedimentation through glycerol shows that BNPI cofractionates with synaptophysin in the middle of the gradient (Fig. 9B). The synaptic plasma membrane protein syntaxin resides predominantly in heavy membranes but also occurs at low levels on synaptic vesicles (Fig. 9B) (Walch-Solimena et al., 1995). Importantly, the heavy membrane fractions contain very little BNPI when compared with the synaptic vesicle fractions, indicating extremely low synaptophysin
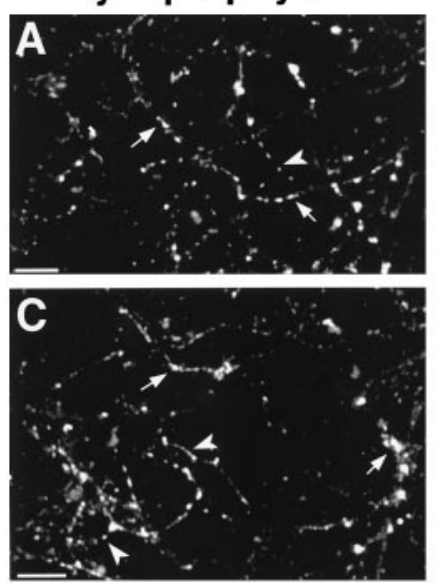

Figure 6. BNPI colocalizes with synaptophysin at a subset of varicosities in primary hippocampal cultures. After $14 \mathrm{~d}$ in vitro, primary hippocampal cultures from E19 rats were double-labeled for the synaptic vesicle marker synaptophysin $(A, C)$ and BNPI $(B, D)$. Synaptophysin was detected with a mouse monoclonal antibody and BNPI with the rabbit polyclonal antibody. The primary antibodies were recognized with appropriate secondary antibodies conjugated to rhodamine $(A, C)$ and fluorescein $(B, D)$. Examination of two fields $(A, B$ and $C, D)$ shows that synaptophysin distributes in a punctate manner along neuronal processes (arrows). Essentially all BNPI immunoreactivity distributes in a similar manner, colocalizing with synaptophysin at synaptic structures (arrows). However, many synaptophysin-immunoreactive synapses do not label for BNPI (arrowheads), indicating that BNPI localizes to a subset of terminals. Scale bars, $20 \mu \mathrm{m}$. 

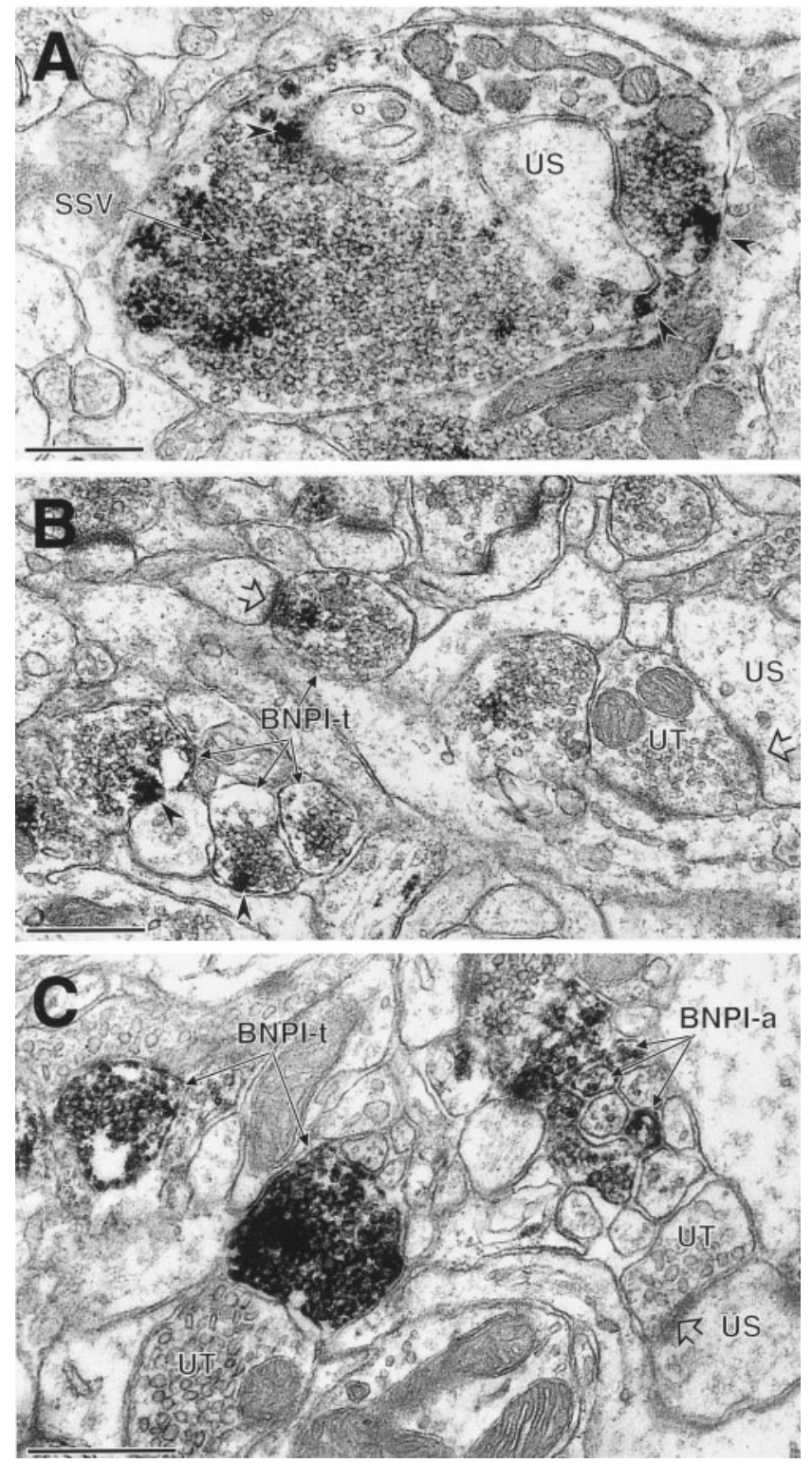

Figure 7. BNPI localizes to excitatory-type terminals in the rat hippocampal formation and caudate putamen nucleus. $A$, In stratum lucidum of the CA3 region of the hippocampus, BNPI peroxidase labeling is seen in a large, complex mossy fiber terminal that contacts an unlabeled spine $(U S)$. Although this section does not demonstrate unequivocally the asymmetric nature of the synapse, all mossy fiber terminals form exclusively asymmetric synapses onto dendritic spines (Amaral and Dent, 1981). Within the mossy fiber terminal the peroxidase reaction product is distributed diffusely around the membranes of numerous small synaptic vesicles $(S S V)$. Intense labeling also occurs near the plasma membrane (arrowheads), where it appears to overlie large dense core vesicles. B, In the hilar layer of the dentate gyrus, several small axon terminals (BNPI- $t$ ) contain peroxidase labeling for BNPI that is associated with putative dense core vesicles near the plasma membrane (arrowheads). One of these labeled terminals forms an asymmetric synapse (open arrow) with an unlabeled spine. Many unlabeled spines and unlabeled axon terminals are seen in the neuropil. One of the unlabeled terminals (UT) forms an asymmetric synapse (open arrow) with an unlabeled spine (US). C, Intense peroxidase reaction product surrounds the membranes of small vesicles in selected unmyelinated axons (BNPI- $a$ ) and two axon terminals (BNPI- $t$ ) in the dorsal caudate putamen nucleus. Numerous other unlabeled axons and nerve terminals (UT) are present in the neuropil. The unlabeled terminal (UT) on the right forms an asymmetric synapse (open arrowhead) with an unlabeled dendritic spine $(U S)$. Scale bars, $0.5 \mu \mathrm{m}$.
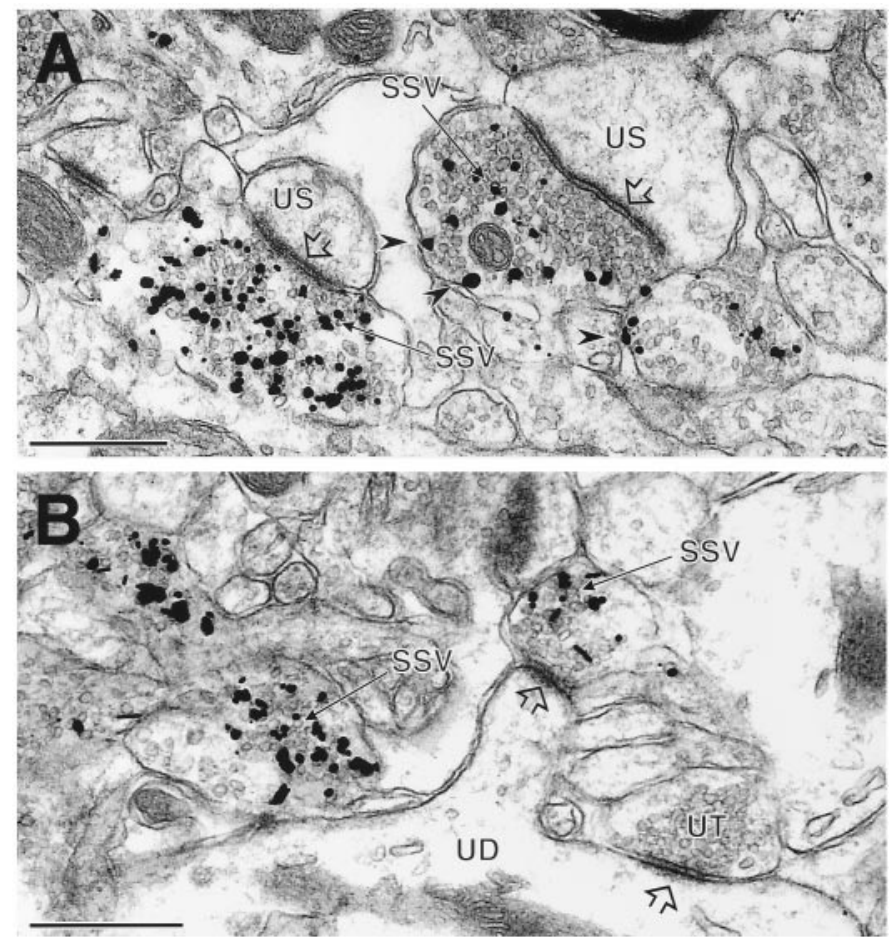

Figure 8. BNPI localizes to synaptic vesicles at asymmetric synapses by immunogold-silver electron microscopy. Immunogold-silver electron microscopy localizes BNPI in axon terminals that form asymmetric excitatory-type synapses (open arrowheads) with unlabeled dendritic shafts $(U D)$ or spines $(U S)$ in the rat caudate putamen nucleus. $A$, Immunogold-silver deposits are seen in direct contact with many small synaptic vesicles $(S S V)$ within the BNPI-labeled terminals. Several gold particles also directly contact the plasma membrane (arrowheads) but only in the vicinity of synaptic vesicles. $B$, Immunogold-silver labeling for BNPI is associated with SSVs in two axon terminals, one of which forms an asymmetric synapse (open arrowhead) with a spine from the unlabeled dendrite $(U D)$. An adjacent unlabeled terminal $(U T)$ also forms an asymmetric synaptic contact (open arrowhead) with the shaft of the same dendrite. Scale bars, $0.5 \mu \mathrm{m}$.

levels of expression at the plasma membrane. Thus, BNPI localizes to synaptic vesicles by biochemical fractionation as well as by immunoelectron microscopy.

\section{DISCUSSION}

The antibody to BNPI that we describe here specifically recognizes a protein of the anticipated size in both transfected cells and the rat brain. Although rat kidney expresses distinct $\mathrm{Na}^{+}$dependent $\mathrm{P}_{\mathrm{i}}$ transporters ( $\mathrm{Li}$ and Xie, 1995), their sequences diverge substantially from BNPI at the C terminus used to produce antigen, making it unlikely that the BNPI antibody crossreacts with these proteins.

\section{BNPI localizes to nerve terminals at excitatory synapses}

The results indicate that BNPI localizes to nerve terminals. By light microscopy it has been shown that the BNPI antibody selectively labels structures that resemble nerve terminals and does not label cell bodies or dendritic structures. Electron microscopy confirms the presynaptic expression of BNPI. Further, essentially all BNPI immunoreactivity colocalizes with that of synaptophysin in primary hippocampal cultures. However, many varicosities in the cultures express synaptophysin, but not BNPI. BNPI thus appears to localize only to a subset of nerve terminals. 
A
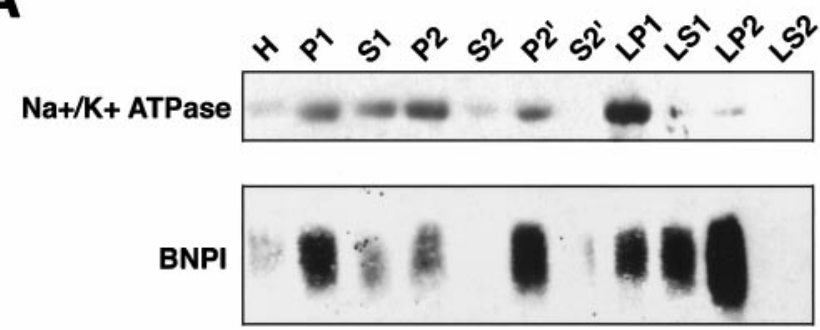

synaptophysin

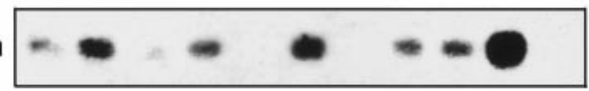

B

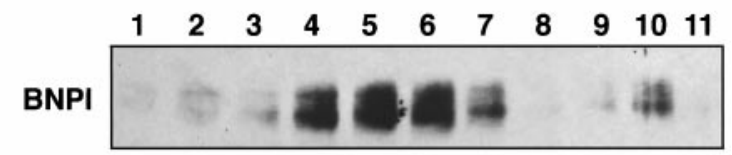

synaptophysin

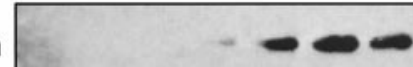

syntaxin

syntaxin $=-m+20$

Figure 9. BNPI resides on synaptic vesicles by differential centrifugation and velocity sedimentation. $A$, Synaptosomes and synaptic vesicles were prepared from rat brain. Equal amounts of protein from each fraction were loaded into lanes and analyzed by Western analysis. BNPI appears in both the insoluble debris $(P 1)$ and postnuclear supernatant $(S 1)$. Further, BNPI sediments with the plasma membrane marker $\mathrm{Na}^{+} / \mathrm{K}^{+}$-ATPase, the synaptic vesicle marker synaptophysin, and the presynaptic plasma membrane marker syntaxin in the crude synaptosomal fractions $P 2$ and $P 2^{\prime}$ rather than with the high-speed supernatants $S 2$ and $S 2^{\prime}$. After hypo-osmotic lysis of the synaptosomes, the $\mathrm{Na}^{+} / \mathrm{K}^{+}$-ATPase and syntaxin occur principally in $L P 1$, strongly suggesting the localization of plasma membrane fragments to this fraction. In contrast, the first supernatant (LS1) contains more BNPI and synaptophysin than the first pellet (LP1), suggesting localization of BNPI to synaptic vesicles. Further, high-speed sedimentation of $L S 1$ shows localization of both BNPI and synaptophysin to $L P 2$ rather than to $L S 2$. Thus, BNPI cofractionates with synaptophysin rather than with the plasma membrane markers, suggesting localization to a population of synaptic vesicles. B, Fractions $1-11$ were collected from the top of a 5-25\% glycerol velocity gradient of LS1. Western analysis of equal volumes of each fraction shows that BNPI cofractionates with synaptophysin in the middle of the gradient. In contrast, the synaptic plasma membrane marker syntaxin occurs predominantly at the bottom of the gradient. Thus, BNPI occurs on synaptic vesicles rather than on the presynaptic plasma membrane. The small amount of syntaxin cofractionating with synaptophysin presumably reflects the low levels of syntaxin known to occur on synaptic vesicles.

Previous in situ hybridization localizing BNPI to a subset of cell groups in the brain (Ni et al., 1995) was consistent with the expression of BNPI mRNA by glutamatergic neurons. Localization of BNPI protein now indicates a specific role in glutamatergic transmission. The outer two-thirds of the molecular layer in the dentate gyrus show strong immunoreactivity, suggesting the expression of BNPI by glutamatergic inputs from the perforant pathway (Matthews et al., 1976; Johnston and Amaral, 1998). Indeed, the entorhinal cortex, which gives rise to the perforant path, expresses substantial amounts of BNPI mRNA. Light and electron microscopy show that BNPI localizes to excitatory mossy fiber terminals in stratum lucidum of CA3 of the hippocampus, consistent with the expression of BNPI mRNA by dentate gyrus granule cells (Ni et al., 1995). In addition, BNPI localizes to excitatory Schaffer collaterals in strata oriens and radiatum of CA1, and the hippocampal neurons in CA3 from which these collaterals derive express BNPI mRNA (Ni et al., 1995). The laminar pattern of BNPI immunoreactivity in the hippocampus strongly resembles that previously observed for glutamate (Storm-Mathisen et al., 1983). Further, electron microscopic immunolabeling confirms that high levels of BNPI occur at asymmetric excitatory-type terminals in both the hippocampus and caudate putamen nuclei, strongly supporting a role for BNPI in excitatory transmission. Additionally, in hippocampal cultures the neuronal cell bodies express low levels of BNPI, and all of the immunoreactive cells also express PAG, a protein essentially restricted to glutamatergic neurons (Najlerahim et al., 1990; Aoki et al., 1991; Kaneko and Mizuno, 1994; Torgner et al., 1998).

BNPI protein also localizes to excitatory connections in the cerebellum. Excitatory synapses made by climbing and parallel fiber inputs onto Purkinje cell dendrites occur in the molecular layer, and the molecular layer contains high levels of BNPI, consistent with the expression of BNPI mRNA by inferior olivary neurons and granule cells from which climbing and parallel fibers arise. In the granule cell layer the excitatory mossy fiber terminals, which derive from pontine nuclei expressing BNPI mRNA, also label heavily for BNPI. Thus, BNPI protein occurs at glutamatergic synapses (Storm-Mathisen and Ottersen, 1988) in multiple brain regions.

The results also indicate that BNPI does not function in inhibitory transmission. By light microscopy it has been shown that BNPI immunoreactivity differs dramatically from that of GABA and such GABAergic markers as glutamic acid decarboxylase and the vesicular GABA transporter (Storm-Mathisen and Ottersen, 1983; Esclapez et al., 1994; Chaudhry et al., 1998). Consistent with this observation, inhibitory cell populations express no BNPI mRNA (Ni et al., 1995). Electron microscopy confirms that symmetric, presumably inhibitory, synapses do not express detectable BNPI protein. BNPI immunoreactivity in such regions as the caudate putamen that contain abundant GABAergic neurons thus presumably derives from other brain regions, such as the cortex, which do express BNPI mRNA (Ni et al., 1995).

Although restricted to glutamatergic terminals, BNPI expression does not occur at all glutamatergic synapses. In stratum lucidum of the CA3 region of the hippocampus, structures having the light microscopic features of mossy fiber terminals show strong immunoreactivity for BNPI. However, Schaffer collaterals in strata oriens and radiatum of both CA3 and CA1 show much less intense immunoreactivity, indicating heterogeneity of BNPI expression by glutamatergic afferents. Consistent with these observations, thalamic nuclei use glutamate as their neurotransmitter but conspicuously lack BNPI mRNA (Ni et al., 1995). Electron microscopic immunolabeling of both the hippocampus and caudate putamen also shows many nerve terminals forming asymmetric synapses that do not contain BNPI. Thus, BNPI appears to have a specific role only at certain excitatory synapses. 


\section{Potential physiological roles for BNPI at excitatory synapses}

Plasma membrane $\mathrm{P}_{\mathrm{i}}$ transport mediated by BNPI may maintain the level of ATP required for neuronal function (Glinn et al., 1995, 1997). Indeed, a substantial proportion of externally applied ${ }^{32} \mathrm{P}_{\mathrm{i}}$ incorporates into ATP after $\mathrm{Na}^{+}$-dependent uptake into cultured cortical neurons, and the levels of ATP, NADPH, and intracellular-free $\mathrm{P}_{\mathrm{i}}$ in these cells also depend on extracellular $\mathrm{P}_{\mathrm{i}}$. However, the restricted expression of BNPI to particular neuronal populations suggests that BNPI does not have a general role in neuronal function. Rather, BNPI appears to function specifically in a subset of excitatory neurons. Further, the presynaptic localization of BNPI suggests a role in the regulation of glutamate synthesis, accumulation, or release.

Although BNPI belongs to a family of $\mathrm{Na}^{+}$-dependent $\mathrm{P}_{\mathrm{i}}$ transporters, it shows particularly strong sequence similarity to EAT-4, a C. elegans gene product recently implicated in glutamatergic neurotransmission. Originally isolated in screens for genes involved in feeding (Avery, 1993), eat-4 mutants show defects in a number of behaviors, many of which involve the transmitter glutamate (Raizen and Avery, 1994; Dent et al., 1997; Li et al., 1997; Lee, Sawin, Chalfie, Horvitz, and Avery, unpublished observations). However, the iontophoretic application of glutamate at a glutamatergic synapse elicits a normal postsynaptic response (Dent et al., 1997; Li et al., 1997), strongly suggesting a specific presynaptic role for BNPI. Importantly, neurotransmission by serotonin, acetylcholine, and GABA appears normal in eat-4 mutants (Lee, Sawin, Chalfie, Horvitz, and Avery, unpublished observations). Thus, both EAT-4 and its vertebrate homolog BNPI appear to have a specific presynaptic function at glutamatergic connections.

How does BNPI influence glutamate release? BNPI may function specifically in glutamate transport, but a large family of plasma membrane glutamate transporters has been identified already (Arriza et al., 1994; Robinson and Dowd, 1997), and BNPI shows no sequence similarity to these proteins. Although the proteins responsible for vesicular glutamate transport have not yet been identified and we find that BNPI localizes to synaptic vesicles, BN PI clearly functions as a $\mathrm{P}_{\mathrm{i}}$ transporter (Ni et al., 1994, 1996). Furthermore, the dependence on $\mathrm{Na}^{+}$makes it unlikely that BNPI functions in vesicles, where a proton electrochemical gradient provides the principal driving force for the packaging of classical neurotransmitters (for review, see Liu and Edwards, 1997). It seems more likely that BNPI contributes to the synthesis of glutamate at the nerve terminal.

An isoform of the enzyme glutaminase synthesizes a majority of the glutamate available for $\mathrm{Ca}^{2+}$-dependent synaptic release (Bradford et al., 1978; Hamberger et al., 1979a,b; Ward et al., 1983; Szerb and O'Regan, 1985). This glutaminase localizes to a subset of glutamatergic fibers (Aoki et al., 1991; Kaneko and Mizuno, 1994; Torgner et al., 1998). Within neurons, the glutaminase associates with mitochondria and synaptic vesicles (Aoki et al., 1991) and also occurs in a soluble form (Torgner et al., 1998). Interestingly, $\mathrm{P}_{\mathrm{i}}$ prominently activates this glutaminase, accounting for its designation as PAG (EC 3.5.1.2) (Curthoys and Watford, 1995). Because PAG has a $K_{1 / 2}^{1 / 2}$ for $\mathrm{P}_{\mathrm{i}}$ of $10-25 \mathrm{~mm}$, physiological changes in cytoplasmic $\mathrm{P}_{\mathrm{i}}$ have the potential to regulate PAG activity (for review, see Erecinska and Silver, 1990). CSF contains $\sim 100$-fold lower levels of $P_{i}$ (Fishman, 1992) than the $K_{1 / 2}$ for $\mathrm{P}_{\mathrm{i}}$, suggesting that the active accumulation of $\mathrm{P}_{\mathrm{i}}$ catalyzed by BNPI may elevate cytoplasmic levels substantially.
BNPI therefore may regulate glutamate synthesis and release. This role is consistent with both the glutamatergic phenotype of the eat-4 mutant in C. elegans and the localization of vertebrate BNPI to excitatory nerve terminals.

In addition to glutamate, PAG produces ammonia. In the kidney, PAG contributes to the elimination of acid from the body by producing ammonia, which diffuses into the lumen of the nephron and buffers the protons secreted into the urine (Lote, 1994; Curthoys and Watford, 1995). Protonation of ammonia in the lumen of the nephron yields ammonium ions for which the charge prevents diffusion back across the renal epithelium. Similarly, the ammonia produced by PAG in glutamatergic neurons may diff use into synaptic vesicles, and the protonation occurring in this acidic compartment presumably would prevent diffusion back to the cytoplasm. Ammonia produced by PAG thus may reduce the $\mathrm{pH}$ gradient across the vesicle membrane and increase the electrical component of the proton electrochemical gradient. Importantly, the transport of glutamate into synaptic vesicles differs from the transport of other classical transmitters: glutamate transport depends more on the electrical component of the proton electrochemical gradient than on the $\mathrm{pH}$ gradient (Maycox et al., 1988; Carlson et al., 1989). PAG therefore has the potential to facilitate glutamate release by producing ammonia as well as glutamate.

\section{Localization of BNPI to synaptic vesicles suggests regulation of $\mathrm{BNPI}$ function}

Although its dependence on $\mathrm{Na}^{+}$suggests that BNPI functions at the plasma membrane, the results indicate that the majority of BNPI resides on synaptic vesicles. Immunoelectron microscopy demonstrates that the vast majority of BNPI localizes to synaptic vesicles in axon terminals forming asymmetric synapses. In addition, the localization of BNPI to synaptic vesicles by biochemical methods excludes the possibility that we have failed to detect BNPI at the plasma membrane because of problems associated with fixation or protein-protein interactions. Because the dependence of BNPI on a $\mathrm{Na}^{+}$rather than $\mathrm{H}^{+}$gradient makes it unlikely that the transporter functions in synaptic vesicles, we presume that the localization to synaptic vesicles provides a mechanism for precisely regulated cell-surface expression and function. In particular, the appearance of BNPI at the plasma membrane on synaptic vesicle exocytosis would allow neural activity to increase glutamate synthesis via the activation of PAG. Interestingly, unlike neuronal populations that use other neurotransmitters, glutamatergic neurons appear to lack a presynaptic reuptake system to replenish released transmitter (Rothstein et al., 1994; Lehre et al., 1995; Velaz-Faircloth et al., 1996; Arriza et al., 1997). BNPI therefore may provide an alternative mechanism to replenish glutamate stores after massive exocytosis. The low steady-state level of BNPI at the plasma membrane also suggests that protracted increases in cytoplasmic $\mathrm{P}_{\mathrm{i}}$, and hence glutamate synthesis, may be deleterious.

In conclusion, we show that BNPI localizes specifically to the presynaptic element at excitatory synapses, consistent with the defect in glutamate release observed in eat-4 mutants in $C$. elegans. Although the function of BNPI in glutamatergic transmission remains unknown, BNPI may serve to stimulate phosphate-activated glutaminase and hence increase the synthesis of glutamate. Surprisingly, BNPI resides on synaptic vesicles rather than on the plasma membrane, suggesting precise temporal regulation of its cell-surface expression and function by neural activity. 


\section{REFERENCES}

Amaral DG, Dent JA (1981) Development of the mossy fibers of the dentate gyrus. I. A light and electron microscopic study of the mossy fibers and their expansions. J Comp Neurol 195:51-86.

Aoki C, Kaneko T, Starr A, Pickel VM (1991) Identification of mitochondrial and non-mitochondrial glutaminase within select neurons and glia of rat forebrain by electron microscopic immunocytochemistry. J Neurosci Res 28:531-548.

Arriza JL, Fairman WA, Wadiche JI, Murdoch GH, Kavanaugh MP, Amara SG (1994) Functional comparison of three glutamate transporter subtypes cloned from human motor cortex. J Neurosci 14:5559-5569.

Arriza JL, Eliasof S, Kavanaugh MP, Amara SG (1997) Excitatory amino acid transporter 5 , a retinal glutamate transporter coupled to a chloride conductance. Proc Natl Acad Sci USA 94:4155-4160.

Avery L (1993) The genetics of feeding in Caenorhabditis elegans. Genetics 133:897-917.

Bennett MK, Garcia-Arraras JE, Elferink LA, Peterson K, Fleming AM, Hazuka CD, Scheller RH (1993) The syntaxin family of vesicular transport receptors. Cell 74:863-873.

Bradford HF, Ward HK, Thomas AJ (1978) Glutamine-a major substrate for nerve endings. J Neurochem 30:1453-1459.

Brewer GJ, Torricelli JR, Evege EK, Price PJ (1993) Optimized survival of hippocampal neurons in B27-supplemented Neurobasal, a new serum-free medium combination. J Neurosci Res 35:567-576.

Caldwell PC, Lowe AG (1970) The influx of orthophosphate into squid giant axons. J Physiol (Lond) 207:271-280.

Carlson MD, Kish PE, Ueda T (1989) Characterization of the solubilized and reconstituted ATP-dependent vesicular glutamate uptake system. J Biol Chem 264:7369-7376.

Chan J, Aoki C, Pickel VM (1990) Optimization of differential immunogold-silver and peroxidase labeling with maintenance of ultrastructure in brain sections before plastic embedding. J Neurosci Methods 33:113-127.

Chaudhry FA, Reimer RJ, Bellocchio EE, Danbolt NC, Osen KK, Edwards RH, Storm-Mathisen J (1998) The putative vesicular GABA transporter "VGAT" localizes to synaptic vesicles in sets of glycinergic as well as GABAergic neurons. J Neurosci, in press.

Clift-O'Grady L, Linstedt AD, Lowe AW, Grote E, Kelly RB (1990) Biogenesis of synaptic vesicle-like structures in a pheochromocytoma cell line PC-12. J Cell Biol 110:1693-1703.

Curthoys NP, Watford M (1995) Regulation of glutaminase activity and glutamine metabolism. Annu Rev Nutr 15:133-159.

Dent JA, Davis MW, Avery L (1997) avr-15 encodes a chloride channel subunit that mediates inhibitory glutamatergic neurotransmission and ivermectin sensitivity in Caenorhabditis elegans. EMBO J 16:5867-5879.

Erecinska M, Silver IA (1990) Metabolism and role of glutamate in mammalian brain. Prog Neurobiol 35:245-296.

Esclapez M, Tillakaratne NJK, Kaufman DL, Tobin AJ, Houser CR (1994) Comparative localization of two forms of glutamic acid decarboxylase and their mRNAs in rat brain supports the concept of functional differences between the forms. J Neurosci 14:1834-1855.

Finn III JP, Edwards RH (1997) Individual residues contribute to multiple differences in ligand recognition between vesicular monoamine transporters 1 and 2. J Biol Chem 272:16301-16307.

Fishman RA (1992) Composition of the cerebrospinal fluid. In: Cerebrospinal fluid in diseases of the nervous system, p 250. Philadelphia: Saunders.

Furman S, Lichtstein D, Ilani A (1997) Sodium-dependent transport of phosphate in neuronal and related cells. Biochim Biophys Acta 1325:34-40.

Glinn M, Ni B, Paul SM (1995) Characterization of $\mathrm{Na}^{+}$-dependent phosphate uptake in cultured fetal rat cortical neurons. J Neurochem 65:2358-2365.

Glinn M, Ni B, Paul SM (1997) Inorganic phosphate enhances phosphonucleotide concentrations in cultured fetal rat cortical neurons. Brain Res 757:85-92.

Hamberger AC, Chiang GH, Nylen ES, Scheff SW, Cotman CW (1979a) Glutamate as a CNS transmitter. I. Evaluation of glucose and glutamine as precursors for the synthesis of preferentially released glutamate. Brain Res 168:513-530.

Hamberger A, Chiang GH, Sandoval E, Cotman CW (1979b) Glutamate as a CNS transmitter. II. Regulation of synthesis in the releasable pool. Brain Res 168:531-541.

Haug FMS, Blackstad TW, Simonsen AH, Zimmer J (1971) Timm's sulfide silver reaction for zinc during experimental anterograde degeneration of hippocampal mossy fibers. J Comp Neurol 142:22-32.

Huttner WB, Schiebler W, Greengard P, De Camilli P (1983) Synapsin I (protein I), a nerve terminal-specific phosphoprotein. III. Its association with synaptic vesicles studied in a highly purified synaptic vesicle preparation. J Cell Biol 96:1374-1388.

Jahn R, Schiebler W, Ouimet C, Greengard P (1985) A 38,000-dalton membrane protein $(\mathrm{p} 38)$ present in synaptic vesicles. Proc Natl Acad Sci USA 82:4137-4141.

Johnston D, Amaral DG (1998) Hippocampus. In: The synaptic organization of the brain (Shepherd GM, ed), pp 417-458. New York: Oxford UP.

Kaneko T, Mizuno N (1994) Glutamate-synthesizing enzymes in GABAergic neurons of the neocortex: a double immunofluorescence study in the rat. Neuroscience 61:839-849.

Lehre KP, Levy LM, Ottersen OP, Storm-Mathisen J, Danbolt NC (1995) Differential expression of two glial glutamate transporters in the rat brain: quantitative and immunocytochemical observations. J Neurosci 15:1835-1853.

Leranth C, Pickel VM (1989) Electron microscopic pre-embedding double immunostaining methods. In: Neuroanatomical tract-tracing methods. II. Recent progress (Heimer L, Zaborsky L, eds), pp 129-172. New York: Plenum.

Li H, Xie Z (1995) Molecular cloning of two rat $\mathrm{Na}^{+} / \mathrm{P}_{\mathrm{i}}$ cotransporters: evidence for differential tissue expression of transcripts. Cell Mol Biol Res 41:451-460.

Li H, Avery L, Denk W, Hess GP (1997) Identification of chemical synapses in the pharynx of Caenorhabditis elegans. Proc Natl Acad Sci USA 94:5912-5916.

Liu Y, Edwards RH (1997) The role of vesicular transport proteins in synaptic transmission and neural degeneration. Annu Rev Neurosci 20:125-156.

Llinás RR, Walton KD (1998) Cerebellum. In: The synaptic organization of the brain (Shepherd GM, ed), pp 255-288. New York: Oxford UP.

Lote CJ (1994) Renal regulation of body fluid pH. In: Principles of renal physiology, pp 121-140. New York: Chapman and Hall.

Matthews DA, Cotman C, Lynch G (1976) An electron microscopic study of lesion-induced synaptogenesis in the dentate gyrus of the adult rat. I. Magnitude and time course of degeneration. Brain Res 115:1-21.

Maycox PR, Deckwerth T, Hell JW, Jahn R (1988) Glutamate uptake by brain synaptic vesicles: energy dependence of transport and functional reconstitution in proteoliposomes. J Biol Chem 263:15423-15428.

Mullins LJ (1954) Phosphate exchange in nerve. J Cell Comp Physiol 44:77-86.

Murer H, Biber J (1996) Molecular mechanisms of renal apical Na/ phosphate cotransport. Annu Rev Physiol 58:607-618.

Najlerahim A, Harrison PJ, Barton AJL, Heffernan J, Pearson RCA (1990) Distribution of messenger RNAs encoding the enzymes glutaminase, aspartate aminotransferase, and glutamic acid decarboxylase in rat brain. Mol Brain Res 7:317-333.

Ni B, Rosteck Jr PR, Nadi NS, Paul SM (1994) Cloning and expression of a cDNA encoding a brain-specific $\mathrm{Na}^{+}$-dependent inorganic phosphate cotransporter. Proc Natl Acad Sci USA 91:5607-5611.

Ni B, Wu X, Yan G-M, Wang J, Paul SM (1995) Regional expression and cellular localization of the $\mathrm{Na}^{+}$-dependent inorganic phosphate cotransporter of rat brain. J Neurosci 15:5789-5799.

Ni B, Du Y, Wu X, DeHoff BS, Rosteck Jr PR, Paul SM (1996) Molecular cloning, expression, and chromosomal localization of a human brain-specific $\mathrm{Na}^{+}$-dependent inorganic phosphate cotransporter. J Neurochem 66:2227-2238.

Palay SL, Chan-Palay V (1974) The mossy fibers. In: Cerebellar cortex: cytology and organization, pp 142-179. New York: Springer.

Paxinos G, Watson C (1986) The rat brain in stereotaxic coordinates. New York: Academic.

Raizen DM, Avery L (1994) Electrical activity and behavior in the pharynx of Caenorhabditis elegans. Neuron 12:483-495.

Robinson MB, Dowd LA (1997) Heterogeneity and functional properties of subtypes of sodium-dependent glutamate transporters in the mammalian central nervous system. In: Advances in pharmacology (August JT, Anders MW, Murad F, Coyle JT, eds), pp 69-115. San Diego: Academic. 
Rothstein JD, Martin L, Levey AI, Dykes-Hoberg M, Jin L, Wu D, Nash N, Kuncl RW (1994) Localization of neuronal and glial glutamate transporters. Neuron 13:713-725.

Storm-Mathisen J, Ottersen OP (1983) Immunohistochemistry of glutamate and GABA. In: Glutamine, glutamate, and GABA in the central nervous system (Hertz L, Kvamme E, McGeer EG, Schousboe A, eds), pp 185-201. New York: Liss.

Storm-Mathisen J, Ottersen OP (1988) Anatomy of putative glutamatergic neurons. In: Neurotransmitters and cortical function: from molecules to mind (Avoli M, Reader TA, Dykes RW, Gloor P, eds), pp 39-70. New York: Plenum.

Storm-Mathisen J, Leknes AK, Bore AT, Vaaland JL, Edminson P, Haug F-MS, Ottersen OP (1983) First visualization of glutamate and GABA in neurones by immunocytochemistry. Nature 301:517-520.

Szerb JC, O'Regan PA (1985) Effect of glutamine on glutamate release from hippocampal slices induced by high $\mathrm{K}^{+}$or by electrical stimulation: interaction with different $\mathrm{Ca}^{2+}$ concentrations. $\mathrm{J}$ Neurochem 44:1724-1731.
Torgner IA, Laake JH, Roberg B, Kvamme E, Takumi Y, Ottersen OP (1998) Phosphate-activated glutaminase-like immunoreactivity diverges strongly among glutamatergic pathways in rat cerebellum. J Neurochem 71:S88.

Velaz-Faircloth M, McGraw TS, Malandro MS, Fremeau Jr RT, Kilberg MS, Anderson KJ (1996) Characterization and distribution of the neuronal glutamate transporter EAAC1 in rat brain. Am J Physiol 270:C67-C75.

Walch-Solimena C, Blasi J, Edelmann L, Chapman ER, von Mollard GF, Jahn R (1995) The t-SNAREs syntaxin 1 and SNAP-25 are present on organelles that participate in synaptic vesicle recycling. J Cell Biol 128:637-645.

Ward HK, Thanki CM, Bradford HF (1983) Glutamine and glucose as precursors of transmitter amino acids: ex vivo studies. J Neurochem 40:855-860.

Werner A, Moore ML, Mantei N, Biber J, Semenza G, Murer H (1991) Cloning and expression of cDNA for a $\mathrm{Na} / \mathrm{P}_{\mathrm{i}}$ cotransport system of kidney cortex. Proc Natl Acad Sci USA 88:9608-9612. 